\title{
Reviews
}

\section{Miquel Àngel Campos Pardillos. Vocabulari comercial anglés/catalä/castellà. Alicante: Secretariado de Publicaciones de la Universidad de Alicante, 1992, 112 pp.}

We are living in the era of global communication and this is so in all fields of life, but is especially true if we refer to the areas of science and knowledge. It is no longer possible to live in our own private "castle" believing that it is an enclosure that exclusively belongs to us and the group of researchers that happen to be interested in the same subject. For the same reason we cannot adopt a closed attitude towards the contributions made by other scholars, thinking that we do not need to pay attention to anyone or anything that is not directly related to the "club" which we are supposed to belong to.

Indeed, the notions of exclusiveness and "watertight compartments" no longer hold for scientific research in general, and they surely do not in the case of linguistic research. It must be remembered that language is the product of a social community, and as such it represents each and every aspect of the life of that human group. When one studies language one will find a certain amount of elements that can be considered strictly intralinguistic, but, at the same time, it can easily be seen that it would be completely impossible to understand many other aspects of language unless we attend to extralinguistic fields. Many different researchers have clearly proved that in studies focusing on language as a whole, but this open approach becomes practically indispensable if we are dealing with specific languages that are more or less restricted to a particular professional or cultural environment.

The above explanations lead us to a field of research that is slowly but steadily gaining ground in recent years: we are referring to Languages for Specific Purposes. In the case of English, we can see that a very important development of this approach has already taken place. Of course, all this represents a very important change in people's attitudes. The traditional belief according to which the areas of Sciences and Humanities were conceived of as separate worlds lacking any sort of communication clearly proves to be untrue. Lots of publications have shown that the collaboration between researchers from both fields can be extremely fruitful.

The main point when we decide to undertake the task of studying these Languages for Specific Purposes is that we have to adopt a totally new perspective. We cannot stick to the techniques that we have been applying for years when teaching what is usually known as general language, because, above all, the circumstances under which these linguistic corpuses develop are very different from those corresponding to the general language and that distinction is going to give rise to a sharp contrast in terms of characteristic features, communicative objectives and so on.

In this respect, when people start to learn a language, the first thing they have to decide is what their needs are as regards that language. Once we have decided which our 
interests are we shall be able to identify the linguistic aspects that are going to be most relevant to us. This is more clearly true in the field of Languages for Specific Purposes. If we talk about the case of English for Specific Purposes, we can say that the students who have to work with this kind of technical or professional languages very well know what is essential for them. Reasons such as lack of time or the status of English in the context of their studies justify the fact that these people should prefer to concentrate their attention on certain aspects of learning to the detriment of others. Of course, this decision is going to be directly related to the most essential needs they will eventually have to face in their professional practice. Nothing can be said in general, but one can see that aspects like translation, techniques of reading and oral comprehension as well as a basic communicative competence will be favoured. Teachers must be equally aware of all these circumstances when they decide to deal with this material and with this group of learners, and they must try to look for any new possibilities that may enable them to make the most of their teaching and may enhance their students' interest and progress. This is precisely what Miquel Àngel Campos Pardillos is trying to do with this dictionary of Commercial English.

Vocabulari comercial anglés/català/castellà provides an excellent source of information on the field of Commercial and Business English, which is, by the way, one of the most important varieties of English for Specific Purposes.

This relevance of Commercial English is surely no surprise to anyone as we could say we are in the age of economy. Everybody is familiar with economic terms, and words or expressions like shares, the Stock Exchange or the Gross Domestic Product are known to most of us. In fact, this linguistic material is so well-known that people sometimes have come to the point of using some of these units in an idiomatic way, thus greatly extending their meaning, for example, by giving them metaphorical shades and finally changing the status of this once restricted language that becomes a part of everyday speech.

Miquel Àngel Campos Pardillos has a deep knowledge of the whole world of Economics, Commerce and Business and he has made a very important contribution by compiling an important amount of words and expressions with the aim of helping students go through this forest of terminology. This dictionary is surely going to fulfil this aim, and learners will be really thankful to have this kind of reference material at their disposal.

It must be underlined that Miquel Àngel Campos Pardillos has done more than just gathering a list of words in alphabetical order. First of all, his presentation of the material is very clear and he has likewise taken a lot of care in trying to help students in all senses.

On the other hand, he uses abbreviations that are very useful as they offer a concise but also clear grammatical description of each entry, a kind of information that is of paramount importance if one wants to make sure that students will make the appropriate use of the different words and expressions when they use them actively in the written or in the spoken language.

Furthermore, we must also emphasize the author's effort in trying to make his dictionary as useful as possible. He is working with three languages, namely English, Catalan and Spanish, and he takes good advantage of this, by presenting the material from the perspective of each of these three languages, with English first, then Catalan and finally Spanish heading three separate lists of words and expressions. 
This technique is extremely interesting as it offers students the possibility of working with translations and equivalences in all directions, which will enable them to develop their linguistic skills in a considerable way.

Another very relevant aspect about this reference book is that it does not only give a list of terms but also offers some very useful additional sections in which the author completes his contribution. One of them deals with formulas and typical expressions in commercial letters, for which the equivalences with Catalan and Spanish are provided. The other additional section is equally worthy of mention, as it will be very much appreciated by students as well as teachers. Miquel Àngel Campos Pardillos has gathered a series of common mistakes made by students, and explains why they appear and at the same time gives hints that can be helpful to avoid them.

These last two sections further reinforce the conception that is clearly behind this work, the author's didactic aim. As a lecturer in Commercial English at the University of Alicante, the author very well knows the problems and needs of his students, and decidedly faces them making a very important contribution in the form of an instrument to improve their level of English that certainly achieves all its objectives and which, I am sure, students will be thankful for.

Finally, it must also be said that, since the author has used both Spanish and Catalan, this dictionary can go well beyond the academic context and will surely become a useful reference material for the Civil Service both in Spain as a whole and in the context of the autonomous regions in which Catalan is used; besides, it will no doubt be a very useful tool for all kinds of enterprises, specially those which are involved in export-import trade.

Víctor Manuel Pina Medina

\section{Hayden White. Metahistory: The Historical Imagination in Nineteenth-Century Europe. Baltimore: Johns Hopkins UP, 1973, 448 pp. - Hayden White. The Content of the Form: Narrative Discourse and Historical Representation. Baltimore: Johns Hopkins UP, 1987, 244 pp.}

Although fourteen years have elapsed between the two works reviewed here, the purpose of them both still remains unaltered. Along with Louis O. Mink and Paul Ricoeur, Hayden White is today a most outstanding instance of the contemporary tendency to regard narrative as the fundamental form of historical construction and understanding - that is, the inclination to regard history less as a manner of representing reality than as a way of telling as well as of organizing events. Although this view, which can also be observed in the works of other theorists such as Jean-François Lyotard, in some sense partakes of the postmodern thrust to conceive reality as textually (or discursively) construed, his purpose is more humanistic than deconstructive. In fact, White withdraws himself from many forms of postmodern "pantextualism" insofar as he preserves the differences between reality and fiction, on the one hand, and between fiction and history, on the other. This enables him to study historiography-and its relation to culture-with a more encompassing method than many critics (Derrida, Foucault, or Hillis Miller, for instance), 